Bond University

Research Repository

\title{
Influence of Periodizing Dietary Carbohydrate on Iron Regulation and Immune Function in Elite Triathletes
}

McKay, Alannah K A; Heikura, Ida A; Burke, Louise M; Peeling, Peter; Pyne, David B; van Swelm, Rachel P L; Laarakkers, Coby M; Cox, Gregory R

Published in:

International Journal of Sport Nutrition and Exercise Metabolism

DOI:

10.1123/ijsnem.2019-0131

Licence:

Other

Link to output in Bond University research repository.

Recommended citation(APA):

McKay, A. K. A., Heikura, I. A., Burke, L. M., Peeling, P., Pyne, D. B., van Swelm, R. P. L., Laarakkers, C. M., \& Cox, G. R. (2020). Influence of Periodizing Dietary Carbohydrate on Iron Regulation and Immune Function in Elite Triathletes. International Journal of Sport Nutrition and Exercise Metabolism, 30(1), 34-41. https://doi.org/10.1123/ijsnem.2019-0131

\section{General rights}

Copyright and moral rights for the publications made accessible in the public portal are retained by the authors and/or other copyright owners and it is a condition of accessing publications that users recognise and abide by the legal requirements associated with these rights.

For more information, or if you believe that this document breaches copyright, please contact the Bond University research repository coordinator 


\section{Abstract}

2 Sleeping with low carbohydrate $(\mathrm{CHO})$ availability is a dietary strategy that may enhance training

3 adaptation. However, the impact on an athlete's health is unclear. This study quantified the effect of

4 a short-term "sleep-low" dietary intervention on markers of iron regulation and immune function in

5 athletes. In a randomized, repeated measures design, 11 elite triathletes completed two four-day

6 mixed cycle-run training blocks. Key training sessions were structured such that a high-intensity

7 training (HIT) session was performed in the field on the afternoon of days 1 and 3 , and a low-

8 intensity training (LIT) session on the following morning in the laboratory (days 2 and 4). The

9 ingestion of $\mathrm{CHO}$ was either divided evenly across the day (HIGH), or restricted between the HIT

10 and LIT sessions, so that the LIT session was performed with low CHO availability (LOW). Venous

11 blood and saliva samples were collected prior to and following each LIT session and analyzed for

12 interleukin-6 (IL-6), hepcidin-25 and salivary immunoglobulin-A (s-IgA). Concentrations of IL-6

13 increased acutely after exercise $(\mathrm{p}<0.001)$, but did not differ between dietary conditions or days.

14 Hepcidin-25 increased $3 \mathrm{~h}$ post-exercise $(\mathrm{p}<0.001)$, with the greatest increase evident after the LOW

15 trial on day $2(2.5 \pm 0.9$ fold increase $\pm 90 \% \mathrm{CL})$. The s-IgA secretion rate did not change in response

16 to exercise, however, was highest during the LOW condition on day $4(\mathrm{p}=0.046)$. There appears to

17 be minimal impact on markers of immune function and iron regulation when acute exposure to low

18 CHO availability is undertaken with expert nutrition and coaching input.

20 Key words: sleep low; train low; hepcidin. 


\section{Introduction}

22 Acute carbohydrate $(\mathrm{CHO})$ restriction around exercise can enhance molecular adaptations to training

23 by augmenting cell signaling, gene expression, enzyme activity and lipid oxidation (Impey et al.,

24 2018). These outcomes inform nutritional guidelines, which advise athletes to strategically approach

25 CHO periodization (Jeukendrup, 2017). One strategy is the "sleep low" sequence (Burke et al.,

26 2018), which involves commencing a high-intensity training session in the evening with high $\mathrm{CHO}$

27 availability, before restricting $\mathrm{CHO}$ intake at the subsequent meal and overnight. This protocol

28 supports high quality training for the first session, augmented by an enhanced period of cellular

29 signaling related to delayed restoration of muscle glycogen. The following morning's submaximal

30 exercise session is performed under conditions of low muscle and liver glycogen, promoting higher

31 reliance on fat oxidation, greater metabolic stress and cellular adaptation (Bartlett et al., 2015).

32 While careful integration of such strategies can enhance adaptation and performance (Marquet et al.,

33 2016), the potential implications on athlete health are relatively unknown. Accordingly, concern

34 centers on transient immunodepression associated with endurance exercise, which might otherwise

35 be attenuated by $\mathrm{CHO}$ ingestion. Current research shows that low or declining levels of salivary

36 immunoglobulin-A (s-IgA) are associated with increased risk of upper respiratory illness (URI)

37 (Bishop \& Gleeson, 2009); however, both increases (McKay et al., 2018) and decreases (Louis et al.,

38 2016) in s-IgA levels are reported in response to a 3-week periodized CHO intervention; thus, the

39 acute impact of this strategy is unclear.

41 Training with low $\mathrm{CHO}$ availability can also increase post-exercise concentrations of the 42 inflammatory cytokine interleukin-6 (IL-6) (Hennigar et al., 2017), which may have downstream

43 implications for the iron-regulatory hormone hepcidin (Badenhorst et al., 2015). Adherence to a low

$44 \mathrm{CHO}$ diet $(3 \mathrm{~g} / \mathrm{kg})$ for $24 \mathrm{~h}$ can amplify the immediate post-exercise IL-6, and $3 \mathrm{~h}$ post-exercise

45 hepcidin response as compared to high (10 g/kg) $\mathrm{CHO}$ availability (Badenhorst et al., 2015). 
46 Increases in hepcidin levels occur $\sim 3-6$ h post-exercise (Peeling et al., 2009), potentially reducing

47 dietary iron absorption and macrophage iron recycling (Nemeth et al., 2004). Despite the potential

48 long-term implications to athlete health and performance, studies exploring these effects in elite

49 athletes are lacking. Therefore, we quantified the effect of a sleep-low protocol in the daily training

50 environment on markers of inflammation, iron regulation and immune function in elite triathletes.

51 Given that exercise modality can also influence the post-exercise inflammatory response (Nieman et al., 1998), we compared responses between exercise modalities.

\section{Methods}

\section{$55 \quad$ Participants}

56 Four male $(22.5 \pm 3.0 \mathrm{y}, 64.3 \pm 4.1 \mathrm{~kg}, 39 \pm 9 \mathrm{~mm}$ for sum of 7 skinfolds, $74.8 \pm 6.2$ and $76.6 \pm 1.6$ $\mathrm{ml} \cdot \mathrm{kg}^{-1} \cdot \mathrm{min}^{-1}$ for cycle and treadmill $\mathrm{VO}_{2 \text { peak }}$ respectively; mean $\left.\pm \mathrm{SD}\right)$ and seven female $(26.4 \pm 2.0 \mathrm{y}$, $56.4 \pm 5.4 \mathrm{~kg}, 62 \pm 20 \mathrm{~mm}$ for sum of 7 skinfolds, $66.2 \pm 5.1$ and $65.3 \pm 4.4 \mathrm{ml} \cdot \mathrm{kg}^{-1} \mathrm{~min}^{-1}$ for cycle and treadmill $\mathrm{VO}_{2 \text { peak }}$, respectively) triathletes with $>18$ months of elite training history were recruited. Skinfold measurements were undertaken by an accredited anthropometrist according to International Society for the Advancement of Kinanthropometry standards. Athletes were free from injury, illness, or iron deficiency (serum ferritin $>30 \mu \mathrm{g} \cdot \mathrm{L}^{-1}$ ); none were taking iron supplements during the testing period. Written informed consent was obtained prior to participation. Approval was granted by the Australian Institute of Sport (AIS) Ethics Committee.

This study was conducted during an AIS training camp over a 4-week period between two World

67 Triathlon Series events. In a randomized, crossover design athletes completed two 4-day 68 experimental trials with high $\mathrm{CHO}$ availability (HIGH) or adopting an alternate day sleep-low 69 protocol (LOW) (see Figure 1). Athletes completed familiarization tests prior to intervention commencement, from which, workloads for subsequent testing sessions were derived. Tests included

71 a 4-min maximal cycling test to determine cycling $\mathrm{VO}_{2 \text { peak }}$ (Gore et al., 1998) and mean maximal 
72 power (MMP), and a graded treadmill test to determine $\mathrm{VO}_{2 \text { peak }}$ and running velocity at $\mathrm{VO}_{2 \text { peak }}$

$73\left(v \mathrm{VO}_{2}\right)$, as described elsewhere (Tanner \& Gore, 2013)Additionally, a venous blood sample was

74 collected from female athletes to measure sex hormone concentrations and determine menstual

75 phase. Athletes were subsequently pair-matched based on performance measures and menstrual

76 phase, before being randomized into their first dietary condition.

\section{$77 \quad$ Nutrition Interventions}

78 During experimental trials, a standardized daily $\mathrm{CHO}$ intake of 6 (females) or $8 \mathrm{~g} \cdot \mathrm{kg}^{-1}$ body mass

79 (males) was consumed, with differences attributed to disparities in lean body mass and habitual CHO

80 intake between sexes. Athletes completed a directed daily dietary record and ate in a dining hall

81 setting where all meal options where prepared from standardized recipes, allowing free-living with a

82 high degree of dietary control. Athletes were provided with individualized CHO targets for each

83 meal, and were guided to self-select food and fluid to accommodate dietary preferences while

84 meeting dietary targets. A research team member attended all meals to ensure compliance, before

85 undertaking subsequent analysis (Food Works 8 Professional program; Xyris Software Australia Pty

86 Ltd, Australia). Although each athlete's individual CHO intake was matched across experimental

87 trials, $\mathrm{CHO}$ intake was periodized differently across days according to trial allocation. During LOW,

88 a high intensity training (HIT) session was performed in the afternoon to deplete muscle glycogen

89 stores on days 1 and 3 (Table 1). CHO intake was scheduled predominantly pre HIT with post-

90 session consumption restricted $\left(<0.5 \mathrm{gkg}^{-1}\right)$ ahead of a low intensity aerobic session (LIT) the

91 following morning. During $\mathrm{HIGH}$, the $\mathrm{CHO}$ intake was scheduled evenly throughout the day and

92 following the HIT session to facilitate overnight recovery of muscle glycogen stores.

$94 \quad$ Training

95 Athletes completed an individualized training program, involving 3-4 daily sessions of running, 96 swimming, cycling and resistance training (Table 1). Training was structured to include a field-based 
97 HIT session on the afternoons of day 1 and 3, and a laboratory-based LIT session the following

98 morning (day 2 and 4). This design achieved 2 repetitions of the sleep-low protocol within each 4-

99 day period. This protocol incorporated mixed-mode training practices for elite triathletes, with 100 cycling sessions performed on days 1 and 2 and running sessions on days 3 and 4 .

\section{High Intensity Training Sessions}

103 To ensure high external validity and account for the proximity of the upcoming international event,

104 all HIT sessions were individually prescribed and led by an international-level coach who understood

105 the study goals. During the HIT cycling session (day 1), athletes completed an interval-based session 106 ( $\sim 5 \mathrm{~min})$ at an outdoor velodrome on a fixed-gear bike, in addition to cycling to and from the 107 training venue (LOW: $31.2 \pm 5.1 \mathrm{~km}, 76.1 \pm 9.0$ min return; HIGH $28.8 \pm 0.9 \mathrm{~km}, 70.5 \pm 1.9$ min return). 108 The HIT running session (day 3) was interval-based, prescribed from time and/or distance to equal $109 \sim 10 \mathrm{~km}$ (LOW: 53.2 \pm 5.5 min, mean heart rate (HR) 166 \pm 6 bpm; HIGH: $53.2 \pm 9.5$ min, mean HR $110165 \pm 11 \mathrm{bpm})$.

\section{Low Intensity Training Sessions}

113 Athletes reported to the laboratory for LIT sessions at a standardized time in an overnight fasted and

114 rested state. A $4 \mathrm{~mL}$ baseline venous blood sample was collected from an antecubital vein before

115 athletes consumed a snack in accordance with their dietary allocation $\left(1.5 \mathrm{v} 0.0 \mathrm{gkg}^{-1} \mathrm{CHO}\right.$ for 116 HIGH and LOW, respectively); 25 min later, they provided a saliva sample. Thirty min post-snack, 117 athletes commenced their planned LIT task. The 60 min cycle trial (day 2) was performed in the 118 laboratory on the athlete's own bicycle mounted to a stationary cycle ergometer. The 45 min running 119 trial (day 4) was conducted as a hybrid laboratory-field test, with the first and final 5 min completed 120 on a motorized treadmill, and the remainder completed on a flat, outdoor course. The first and final 5 121 min of each trial were completed at $65 \% \mathrm{MMP}$ (cycle) or $\mathrm{vVO}_{2}$ (run) with the remaining distance 
122 completed at $\sim 55 \%$ MMP or $\mathrm{vVO}_{2}$. During $\mathrm{HIGH}$, athletes consumed $0.5 \mathrm{~g}^{\mathrm{kg}} \mathrm{kg}^{-1} \mathrm{CHO}$ during

123 exercise, while water was consumed during LOW. Mean HR and respiratory exchange ratio were

124 determined for the final 5 min of each session, while venous blood and saliva samples were collected

125 immediately and $15 \mathrm{~min}$ post-exercise, respectively. Athletes received a whey protein shake

126 immediately following saliva collection $\left(0.3 \mathrm{~g} \cdot \mathrm{kg}^{-1}\right.$ whey protein) and a CHO-rich breakfast $1 \mathrm{~h}$ post-

127 exercise $\left(2 \mathrm{~g} \cdot \mathrm{kg}^{-1} \mathrm{CHO}\right)$ to ensure recovery and avoid hunger. Venous blood samples were collected

1281 and $3 \mathrm{~h}$ post-exercise.

\section{Experimental Procedures}

131 Blood Sampling

132 Venous blood samples were collected into $4 \mathrm{~mL}$ SST gel separator tubes and left to clot for $30 \mathrm{~min}$ 133 before centrifugation (2200 $\mathrm{G}$ for $10 \mathrm{~min}$ ). Serum was divided into $1 \mathrm{~mL}$ cryotubes and frozen at -

$13480^{\circ} \mathrm{C}$ until batch analysis of iron, serum ferritin, IL-6 and hepcidin- 25 concentrations. Pre-exercise 135 serum iron and ferritin concentrations were quantified via a COBAS Integra 400 automated 136 biochemistry analyzer (Roche Diagnostics, Switzerland). IL-6 concentrations were analyzed in 137 duplicate pre-, post-, $1 \mathrm{~h}$ and $3 \mathrm{~h}$ post-exercise using an ELISA (Quantikine HS, R\&D Systems, 138 Minneapolis, USA; CV=5.7\%). Hepcidin-25 measurements were performed on serum obtained pre139 and $3 \mathrm{~h}$ post-exercise (www.hepcidinanalysis.com, Nijmegen, The Netherlands) using a combination 140 of weak cation exchange chromatography and time-of-flight mass spectrometry (Kroot et al., 2010; 141 Swinkels et al., 2008). When values were below the lower limit of detection of $0.5 \mathrm{nM}$, this value 142 divided by the square root of 2 was used (Croghan \& Egeghy, 2003).

144 Saliva Sampling

145 Prior to, and following each LIT session, an unstimulated saliva sample was obtained 10 min after a $14640 \mathrm{ml}$ water mouth rinse. Prior to sample collection, a $>20$ min window where no $\mathrm{CHO}$ was ingested 
147 was employed to minimize potential sample contamination. Samples were collected using a saliva

148 collection aid (Salimetrics, State College, PA) over a timed 2 min period into $2 \mathrm{ml}$ cryotubes and

149 subsequently weighed. Assuming a saliva density of $1.00 \mathrm{~g} \cdot \mathrm{mL}^{-1}$ (Cole \& Eastoe, 1988), flow rate

$150\left(\mathrm{~mL} \cdot \mathrm{min}^{-1}\right)$ was calculated by multiplying saliva volume by collection time. Samples were

151 centrifuged at $1500 \mathrm{G}$ for $15 \mathrm{~min}$, before s-IgA concentrations were analyzed in duplicate (EIA kits,

152 Salimetrics, State College, PA; CV=5.8\%). Secretion rates $\left(\mu \mathrm{g} \cdot \mathrm{min}^{-1}\right)$ were calculated by multiplying

153 the salivary flow rate by s-IgA concentration.

154 Statistical Analysis

155 Data were analyzed in SPSS (version 25.0, IBM, USA) using a linear mixed model and presented as 156 mean \pm standard deviation. A random intercept for subjects was included to adjust for baseline levels 157 and inter-individual homogeneity. Initial models included all possible interactions, but non158 significant interaction terms were dropped from the models for ease of interpretation.

\section{Results}

160 Self-recorded dietary intakes (Table 2) did not differ for energy, CHO, protein, fat and iron between 161 treatments, however timing of $\mathrm{CHO}$ intake across the day was different. As intended, $\mathrm{CHO}$ intake 162 before the HIT session on days 1 and 3 was markedly lower in HIGH $\left(4.6 \pm 0.6 \mathrm{gkg}^{-1}\right)$ than LOW $163\left(6.7 \pm 1.1 \mathrm{~g}^{\mathrm{kg}} \mathrm{kg}^{-1} ; \mathrm{p}<0.001\right)$, while intakes after HIT were greater in HIGH $\left(2.6 \pm 0.7 \mathrm{~g}^{\mathrm{kg}} \mathrm{gg}^{-1}\right)$ than LOW $164 \quad\left(0.3 \pm 0.1 \mathrm{~g} \cdot \mathrm{kg}^{-1} ; \mathrm{p}<0.001\right)$.

165 Measures of training performance from the morning LIT sessions showed no differences in power 166 output $(\mathrm{F}(1,19)=0.11, \mathrm{p}=0.741)$ or running speed $(\mathrm{F}(1,18)=0.48, \mathrm{p}=0.497)$ between trials (Table 3$)$. 167 Moderately lower RER $(-4.2 \% ; \mathrm{p}<0.001)$ and higher HR $(3.8 \% ; \mathrm{p}=0.053)$ occurred during LOW, 168 compared to HIGH. Moderate increases in HR $(4.7 \% ; \mathrm{p}=0.019)$ and large increases in RER $(8.4 \%$; $169 \mathrm{p}<0.001)$ were evident during cycling compared to running. 
170 Resting serum ferritin levels were $56 \pm 21$ and $52 \pm 16 \mu \mathrm{g} \cdot \mathrm{L}^{-1}$ during $\mathrm{LOW}$, and $50 \pm 17$ and $50 \pm 15 \mu \mathrm{g} \cdot \mathrm{L}-$

$171{ }^{1}$ during HIGH (cycle and run, respectively). No differences in serum ferritin were seen between

172 dietary interventions or exercise modalities ( $>0.05$ ). Concentrations of IL-6 (Figure 2) gradually

173 increased from pre- to $3 \mathrm{~h}$ post-exercise during all trials $(\mathrm{F}(3,161)=28.5, \mathrm{p}<0.001)$. No clear

174 differences between exercise modalities or dietary interventions were evident $(p>0.05)$. Finally,

175 hepcidin-25 increased substantially from pre- to $3 \mathrm{~h}$ post-exercise $(F(1,78)=20.2, \mathrm{p}<0.001)$, with a 176 greater increase seen after cycling than running $(\mathrm{F}(1,78)=4.2, \mathrm{p}=0.043)$. Furthermore, the increase in

177 hepcidin-25 was greatest during cycling when adhering to LOW than $\operatorname{HIGH}(\mathrm{F}(1,78)=5.2, \mathrm{p}=0.026)$.

178 Markers of mucosal immunity (Table 4) showed that s-IgA concentrations increased post-exercise 179 (17-68\%) during all trials $(\mathrm{F}(1,81)=8.6, \mathrm{p}=0.004)$ but were not different between exercise modalities 180 or dietary interventions ( $>00.05)$. Salivary flow rates decreased consistently $(19-39 \%)$ post-exercise $181(\mathrm{~F}(1,81)=4.3, \mathrm{p}=0.042)$, with trivial differences between exercise modalities $(\mathrm{F}(1,81)=0.70, \mathrm{p}=0.404)$ 182 and dietary interventions $(\mathrm{F}(1,81)=0.11, \mathrm{p}=0.917)$. $\mathrm{s}-\operatorname{IgA}$ secretion rates were greater during the 183 LOW run than all other trials $(\mathrm{F}(1,83)=4.1, \mathrm{p}=0.046)$. No other clear differences in $\mathrm{s}-\operatorname{IgA}$ secretion 184 rates were apparent.

\section{Discussion}

187 This study examined the influence of a sequenced periodization of CHO availability ("sleep low") on 188 markers of inflammation, iron metabolism and immune function in elite athletes. No differences in 189 the IL-6 response to exercise between trials or dietary conditions were evident, however, the $3 \mathrm{~h}$ 190 post-exercise hepcidin response was highest during the LOW cycling trial compared to all other 191 trials. Exercise had an acute effect on mucosal immune markers, but differences between trials or 192 dietary conditions were trivial. It appears that acute rescheduling of daily CHO intake to delay 193 glycogen restoration from previous exercise sessions to create low CHO availability for a subsequent 
194 session of low intensity exercise causes minimal perturbations to the immune system or iron 195 regulation in elite triathlon training settings.

197 We investigated the interactions between exercise modality and CHO availability, by exposing run

198 and cycling sessions of equal metabolic stress to two different scenarios of $\mathrm{CHO}$ availability.

199 However, HR and RER measures during LIT sessions were higher during cycling than running, 200 showing our failure to accurately match the exercise intensity between modalities. We attribute this 201 shortcoming to differences between a graded exercise test (run) and a 4 min MMP test (cycle) for 202 prescribing exercise intensity. While both protocols should elicit a similar $\mathrm{VO}_{2 \text { peak }}$ (Gore et al., 203 1998), the lack of cumulative fatigue during the shorter protocol (4 min MMP test) likely resulted in 204 a higher power at $\mathrm{VO}_{2 \text { peak }}$ than during the incremental test. As such, the prescribed cycling power occurred at a higher intensity than the equivalent target pace for running. Therefore, while direct comparison of modalities is not entirely appropriate, this study provides insights on the impact of exercise intensity to iron regulation and the immune system when $\mathrm{CHO}$ availability is manipulated.

208 Importantly, our dietary intervention appears to have been successful, with an increased HR and 209 decreased RER achieved during LOW compared to HIGH, despite the similarity of external 210 workloads. Differences can be attributed to increased metabolic stress and fat utilization in tandem

211 with reductions in endogenous and exogenous CHO availability (Yeo et al., 2008).

213 Increases in s-IgA concentration and decreases in salivary flow rate were evident after each LIT 214 session, which confirms previous findings (Li \& Gleeson, 2004; McKay et al., 2018), where 215 exercise-induced dehydration and activation of the sympathetic nervous system decreased salivary 216 flow rate to elicit a concentrating effect on s-IgA levels (Bishop et al., 2000). When these factors 217 were accounted for, there were no differences in secretion rates between all four LIT trials. It is 218 possible that the low intensity, short duration exercise bout $(45-60 \mathrm{~min})$ failed to achieve a 
219 sufficiently large exercise stress to elicit alterations to immune function. An increase in s-IgA 220 secretion rate was evident from day 2 to day 4 in the LOW condition only, suggestive of enhanced

221 mucosal defense in response to low CHO availability. Indeed, we previously reported increases in 222 resting s-IgA secretion rates while athletes completed a 3-week block of training involving 223 periodized CHO availability (McKay et al., 2018). Conversely, 3-weeks of an alternate day "sleep

224 low" intervention yielded a small decrease in resting s-IgA levels in trained triathletes (Louis et al., 225 2016), however was deemed unlikely to be clinically meaningful and did not impact illness rates.

226 Collectively, it appears that acute 'sleep-low' approaches to training are not detrimental to the 227 immune system when the training performed with low $\mathrm{CHO}$ availability is of short duration and low 228 intensity.

230 Despite inducing differences in metabolism and fuel utilization, training with low CHO availability

231 did not increase the inflammatory response to exercise. Although IL-6 levels can be increased after 232 exercise performed with low muscle glycogen stores (Steensberg et al., 2001), our intervention may 233 not have sufficiently depleted muscle glycogen stores to create functional differences between 234 conditions. Specifically, the HIT sessions performed on days 1 and 3 were coach-designed to balance 235 the study goals with up-coming international competition, and were intended to maximize 236 performance rather than deplete glycogen stores. Conversely, it is possible that the high daily 237 training loads of our triathlete population created intrinsic glycogen depletion patterns that 238 overshadowed the differential effects of timing of dietary intake, particularly since total CHO intake 239 was similar. Furthermore, since the magnitude of the IL-6 increase is exercise duration- and 240 intensity-dependent (Fischer, 2006), the small IL-6 response to a short, LIT session reduces the 241 potential for detection of differences. 
243 Despite the lack of differences in IL-6 concentrations between trials, there was a greater increase in

244 post-exercise hepcidin concentrations following the LOW-LIT cycle session. This is an unexpected

245 outcome if an augmented IL-6 response is considered the primary mechanism for post-exercise

246 hepcidin changes. However, we recently reported that although an increase in IL-6 is necessary to

247 invoke this change, its contribution to the magnitude of hepcidin response in exercise settings

248 appears small (Peeling et al., 2017; McKay et al., 2019) and other factors are likely to be involved.

249 Exercise intensity may be a regulating factor since the augmented response was only evident in the

250 cycling session. These outcomes strengthen the evidence for the intentional planning of LIT sessions

251 during periods of low $\mathrm{CHO}$ availability, since this approach appears to minimize any potential

252 impact on iron metabolism.

253

254 Since maintenance of good health underpins the consistency of training and optimal performance

255 (Raysmith \& Drew, 2016), it is important to understand the impact of emerging sports nutrition

256 strategies on outcomes such as inflammation, iron metabolism and the immune system. The highly

257 applied nature of this study created limitations to experimental control in the general prescription of

258 the training program, as well as catering for individual athlete requirements. However, the fusion of

259 laboratory-based testing within the daily training environment gives our results strong 'real-world'

260 credibility, and outcomes are highly relevant for elite-level triathletes. While we have examined the

261 acute impact of this dietary strategy, the potential long-term effects of repeated bouts of CHO

262 restriction merit further investigation. Our findings suggest periodizing $\mathrm{CHO}$ availability to promote

263 adaptation throughout the training cycle had limited impact on alterations to markers of athlete

264 health, at least when occasional and planned exposure to low $\mathrm{CHO}$ availability was undertaken with

265 expert nutrition and coaching input. Accordingly, when sessions performed with low CHO

266 availability are low intensity and short in duration, there is likely only minimal impact on exercise-

267 induced alterations in immune function and iron regulation. 


\section{Acknowledgements}

269 The support and assistance of the AIS Sports Nutrition and Physiology staff, and Samantha Leyh,

270 Emily Fallon and Shannon Connolly during data collection is gratefully acknowledged. We thank the

271 athletes involved in this study for their commitment and dedication to the training camp.

272 Importantly, this study would not have been possible without the support and willingness of Jamie

273 Turner, Coach of Triathlon Australia's International Performance Centre. This study was financially

274 supported by grants from Australian Catholic University Research Fund, Australian Institute of 275 Sport's High Performance Sport Research Fund, and Triathlon Australia. The study was designed by 276 AKAM, IAH, LMB, PP, DBP, and GRC; data were collected and analyzed by AKAM, IAH, LMB,

277 RvS, CML and GRC; data interpretation and manuscript preparation were undertaken by AKAM,

278 IAH, LMB, PP, DBP, and GRC. All authors approved the final version of the paper. 


\section{References}

280 Badenhorst, C., Dawson, B., Cox, G., Laarakkers, C., Swinkels, D., \& Peeling, P. (2015). Acute dietary carbohydrate manipulation and the subsequent inflammatory and hepcidin responses to exercise. European Journal of Applied Physiology, 115(12), 2521-2530.

Bartlett, J. D., Hawley, J. A., \& Morton, J. P. (2015). Carbohydrate availability and exercise training adaptation: too much of a good thing? European Journal of Sport Science, 15(1), 3-12.

Bishop, N. C., \& Gleeson, M. (2009). Acute and chronic effects of exercise on markers of mucosal immunity. Froniters in Bioscience, 14, 4444-4456.

Bishop, N. C., Blannin, A. K., Armstrong, E., Rickman, M., \& Gleeson, M. (2000). Carbohydrate and fluid intake affect the saliva flow rate and IgA response to cycling. Medicine and Science in Sports and Exercise, 32(12), 2046-2051.

Burke, L. M., Hawley, J. A., Jeukendrup, A., Morton, J. P., Stellingwerff, T., \& Maughan, R. J. (2018). Toward a common understanding of diet-exercise strategies to manipulate fuel availability for training and competition preparation in endurance sport. International Journal of Sport Nutrition and Exercise Metabolism, 28(5), 451-463.

Cole, A. S., \& Eastoe, J. E. (1988). Biochemistry and Oral Biology. London: Wright.

Croghan, C., \& Egeghy, P. (2003). Methods of dealing with values below the limit of detection using SAS. Southern SAS User Group, 22, 24.

Fischer, C. P. (2006). Interleukin-6 in acute exercise and training: what is the biological relevance? Exercise Immunology Review, 12, 6-33. champion track cyclists. Journal of Science and Medicine in Sport, 1(3), 156-170.

302 Hennigar, S. R., McClung, J. P., \& Pasiakos, S. M. (2017). Nutritional interventions and the IL-6 303 response to exercise. The FASEB Journal, 31(9), 3719-3728. 
304 Impey, S. G., Hearris, M. A., Hammond, K. M., Bartlett, J. D., Louis, J., Close, G. L., \& Morton, J. P. (2018). Fuel for the work required: a theoretical framework for carbohydrate periodization and the glycogen threshold hypothesis. Sports Medicine, 48(5), 1031-1048.

307 Jeukendrup, A. E. (2017). Periodized nutrition for athletes. Sports Medicine, 47(1), 51-63.

308 Kroot, J. J., Laarakkers, C. M., Geurts-Moespot, A. J., Grebenchtchikov, N., Pickkers, P., van Ede, 309 A. E., . . . Sweep, F. C. (2010). Immunochemical and mass-spectrometry-based serum hepcidin assays for iron metabolism disorders. Clinical Chemistry, 56(10), 1570-1579.

Li, T., \& Gleeson, M. (2004). The effect of single and repeated bouts of prolonged cycling and circadian variation on saliva flow rate, immunoglobulin A and-amylase responses. Journal of Sports Sciences, 22(11-12), 1015-1024.

Louis, J., Marquet, L.-A., Tiollier, E., Bermon, S., Hausswirth, C., \& Brisswalter, J. (2016). The

Marquet, L.-A., Brisswalter, J., Louis, J., Tiollier, E., Burke, L. M., Hawley, J. A., \& Hausswirth, C. (2016). Enhanced endurance performance by periodization of CHO intake: "sleep low" strategy. Medicine and Science in Sports and Exercise, 48(4), 663-672.

McKay, A. K., Peeling, P., Pyne, D. B., Welvaert, M., Tee, N., Leckey, J. J., . . . Burke, L. M. (2019). Acute carbohydrate ingestion does not influence the post-exercise iron-regulatory

324 McKay, A. K., Pyne, D. B., Peeling, P., Sharma, A. P., Ross, M. L., \& Burke, L. M. (2018). The 325 impact of chronic carbohydrate manipulation on mucosal immunity in elite endurance athletes. Journal of Sports Sciences, 37(5), 553-559. 
327 Nemeth, E., Tuttle, M. S., Powelson, J., Vaughn, M. B., Donovan, A., Ward, D. M., . . . Kaplan, J. (2004). Hepcidin regulates cellular iron efflux by binding to ferroportin and inducing its internalization. Science, 306(5704), 2090-2093.

330 Nieman, D. C., Nehlsen-Cannarella, S. L., Fagoaga, O. R., Henson, D. A., Utter, A., Davis, J. M., ... Butterworth, D. E. (1998). Influence of mode and carbohydrate on the cytokine response to heavy exertion. Medicine and Science in Sports and Exercise, 30(5), 671-678.

Peeling, P., Dawson, B., Goodman, C., Landers, G., Wiegerinck, E. T., Swinkels, D. W., \& Trinder, D. (2009). Effects of exercise on hepcidin response and iron metabolism during recovery. International Journal of Sport Nutrition and Exercise Metabolism, 19(6), 583-597.

Peeling, P., McKay, A. K., Pyne, D. B., Guelfi, K. J., McCormick, R. H., Laarakkers, C. M., . . . Sharma, A. P. (2017). Factors influencing the post-exercise hepcidin-25 response in elite athletes. European Journal of Applied Physiology, 117(6), 1233-1239.

Raysmith, B. P., \& Drew, M. K. (2016). Performance success or failure is influenced by weeks lost to injury and illness in elite Australian track and field athletes: A 5-year prospective study. Journal of Science and Medicine in Sport, 19(10), 778-783.

Steensberg, A., Febbraio, M. A., Osada, T., Schjerling, P., Hall, G., Saltin, B., \& Pedersen, B. K. (2001). Interleukin-6 production in contracting human skeletal muscle is influenced by

345 Swinkels, D. W., Girelli, D., Laarakkers, C., Kroot, J., Campostrini, N., Kemna, E. H., \& Tjalsma, 346 H. (2008). Advances in quantitative hepcidin measurements by time-of-flight mass

348 Tanner, R., Gore, C. (2013). Physiological tests for elite athletes 2nd Edition: Champaign, IL: Human Kinetics. 
350 Thomas, D. T., Erdman, K. A., \& Burke, L. M. (2016). Position of the academy of nutrition and dietetics, dietitians of Canada, and the American college of sports medicine: Nutrition and athletic performance. Journal of the Academy of Nutrition and Dietetics, 116(3), 501-528.

353 Yeo, W. K., Paton, C. D., Garnham, A. P., Burke, L. M., Carey, A. L., \& Hawley, J. A. (2008). Skeletal muscle adaptation and performance responses to once a day versus twice every second day endurance training regimens. Journal of Applied Physiology, 105(5), 1462-1470. 


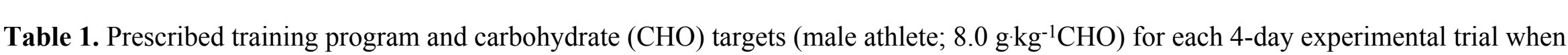
adopting a sleep-low (LOW) and sleep high approach (HIGH). HIT: High-intensity training session; LIT: Low-intensity training session; LSD: Long, slow duration session.

\begin{tabular}{|c|c|c|c|c|c|c|c|c|}
\hline & \multicolumn{2}{|c|}{ DAY 1} & \multicolumn{2}{|c|}{ DAY 2} & \multicolumn{2}{|c|}{ DAY 3} & \multicolumn{2}{|c|}{ DAY 4} \\
\hline & $H I G H$ & $L O W$ & $H I G H$ & $L O W$ & $H I G H$ & $L O W$ & $H I G H$ & $L O W$ \\
\hline Breakfast & $2.5 \mathrm{gkg}^{-1}$ & $3.5 \mathrm{~g} \cdot \mathrm{kg}^{-1}$ & $1.5 \mathrm{gkg}^{-1}$ & $0 \mathrm{~g} \cdot \mathrm{kg}^{-1}$ & $2.5{\mathrm{~g} k g^{-1}}^{-1}$ & $3.5 \mathrm{~g} \cdot \mathrm{kg}^{-1}$ & $1.5{\mathrm{~g} k \mathrm{~kg}^{-1}}$ & $0 \mathrm{gkg}^{-1}$ \\
\hline & \multicolumn{2}{|c|}{ Run } & \multicolumn{2}{|c|}{ LIT Cycle } & \multirow{2}{*}{\multicolumn{2}{|c|}{$\begin{array}{c}\text { Run } \\
20 \text { min LSD } \\
+4 \times 45 \mathrm{sec} \text { builds }\end{array}$}} & \multicolumn{2}{|c|}{ LIT Run } \\
\hline Session 1 & \multicolumn{2}{|c|}{$40 \min$ LSD } & $0.5 \mathrm{gkg}^{-1} \mathrm{CHO}$ & $0 \mathrm{~g}^{\mathrm{kg}}{ }^{-1} \mathrm{CHO}$ & & & $0.5 \mathrm{gkg}^{-1}$ & $0 \mathrm{gkg}^{-1}$ \\
\hline $\begin{array}{l}\text { Post training } \\
\text { Snack }\end{array}$ & & & $2 \mathrm{gkg}^{-1} \mathrm{CHO}$ & $2 \mathrm{~g} \cdot \mathrm{kg}^{-1} \mathrm{CHO}$ & \multicolumn{2}{|c|}{-} & $2 \mathrm{gkg}^{-1}$ & $2 \mathrm{~g} \mathrm{~kg}^{-1}$ \\
\hline Session 2 & \multicolumn{2}{|c|}{$\begin{array}{c}\text { Gym } \\
30 \text { mins }\end{array}$} & & & \multicolumn{2}{|c|}{$\begin{array}{l}\text { Gym } \\
30 \text { mins }\end{array}$} & \\
\hline Session 3 & \multicolumn{2}{|c|}{$\begin{array}{l}\text { Swim } \\
60 \text { min } \\
\text { AT main set }\end{array}$} & \multicolumn{2}{|c|}{$\begin{array}{c}\text { Run } \\
40 \text { min LSD }+6 \text { x } 30 \mathrm{sec} \\
\text { builds }\end{array}$} & \multicolumn{2}{|c|}{$\begin{array}{l}\text { Swim } \\
\quad 60 \text { min } \\
\text { AT main set }\end{array}$} & \multicolumn{2}{|c|}{$\begin{array}{c}\text { Cycle } \\
90 \text { min aerobic }\end{array}$} \\
\hline $\begin{array}{l}\text { Lunch }+ \\
\text { Snacks }\end{array}$ & $2.5 \mathrm{~g} \mathrm{~kg}^{-1}$ & $4 \mathrm{~g} \cdot \mathrm{kg}^{-1}$ & $2 \mathrm{~g} \cdot \mathrm{kg}^{-1}$ & $3 \mathrm{~g} \mathrm{~kg}^{-1}$ & $2.5 \mathrm{~g}^{\mathrm{kg}}{ }^{-1}$ & $4 \mathrm{~g} \mathrm{~kg}^{-1}$ & $2 \mathrm{gkg}^{-1}$ & $3 \mathrm{~g} \mathrm{~kg}^{-1}$ \\
\hline \multirow[t]{2}{*}{ Session 4} & \multicolumn{2}{|c|}{ HIT Cycle } & \multirow{2}{*}{\multicolumn{2}{|c|}{$\begin{array}{l}\text { Swim } \\
60 \mathrm{~min} \\
\text { Aerobic Pull }\end{array}$}} & \multicolumn{2}{|c|}{ HIT Run } & \multirow{2}{*}{\multicolumn{2}{|c|}{$\begin{array}{l}\text { Swim } \\
\quad 60 \mathrm{~min} \\
\text { Aerobic Pull }\end{array}$}} \\
\hline & $0.5 \mathrm{~g}^{\mathrm{kg}}{ }^{-1}$ & $0.5 \mathrm{gkg}^{-1}$ & & & $0.5 \mathrm{gkg}^{-1}$ & $0.5 \mathrm{~g} \cdot \mathrm{kg}^{-1}$ & & \\
\hline Dinner & $2.5 \mathrm{gkg}^{-1}$ & $0{\mathrm{~g} \cdot \mathrm{kg}^{-1}}^{-1}$ & $2 \mathrm{~g} \cdot \mathrm{kg}^{-1}$ & $3 \mathrm{~g}^{\mathrm{kg}} \mathrm{g}^{-1}$ & $2.5 \mathrm{~g} \cdot \mathrm{kg}^{-1}$ & $0{\mathrm{~g} k \mathrm{~kg}^{-1}}$ & $2 \mathrm{~g}^{\mathrm{kg}} \mathrm{g}^{-1}$ & $3{\mathrm{~g} \cdot \mathrm{kg}^{-1}}^{-1}$ \\
\hline
\end{tabular}


Table 2. Daily total energy intake, macronutrient concentrations and daily iron content of athletes when adopting a sleep-low (LOW) and sleep high approach $(\mathrm{HIGH})$; Mean $( \pm \mathrm{SD})$.

\begin{tabular}{|c|c|c|c|c|c|c|c|c|c|}
\hline & & \multicolumn{2}{|c|}{ Day 1} & \multicolumn{2}{|c|}{ Day 2} & \multicolumn{2}{|c|}{ Day 3} & \multicolumn{2}{|c|}{ Day 4} \\
\hline & & LOW & $\mathrm{HIGH}$ & LOW & $\mathrm{HIGH}$ & LOW & HIGH & LOW & $\mathrm{HIGH}$ \\
\hline \multirow[t]{2}{*}{$\operatorname{Energy}\left(\mathrm{kJ} \cdot \mathrm{kg}^{-1}\right)$} & Mean & 277 & 279 & 300 & 299 & 267 & 261 & 293 & 287 \\
\hline & $\mathrm{SD}$ & 38 & 40 & 43 & 37 & 30 & 36 & 39 & 49 \\
\hline \multirow[t]{2}{*}{ Carbohydrate $\left(\mathrm{g} \cdot \mathrm{kg}^{-1}\right)$} & Mean & 7.5 & 7.7 & 7.7 & 8.2 & 6.9 & 7.1 & 7.7 & 8.0 \\
\hline & $\mathrm{SD}$ & 1.3 & 1.2 & 1.4 & 1.6 & 1.1 & 1.1 & 1.3 & 1.5 \\
\hline \multirow[t]{2}{*}{ Fat $\left(\mathrm{g} \cdot \mathrm{kg}^{-1}\right)$} & Mean & 2.3 & 2.5 & 2.9 & 2.7 & 2.4 & 2.3 & 2.8 & 2.4 \\
\hline & $\mathrm{SD}$ & 0.5 & 0.5 & 0.5 & 0.4 & 0.5 & 0.5 & 0.6 & 0.5 \\
\hline \multirow[t]{2}{*}{ Protein $\left(g \cdot \mathrm{kg}^{-1}\right)$} & Mean & 3.4 & 3.1 & 3.2 & 3.3 & 3.1 & 3.0 & 3.4 & 3.4 \\
\hline & $\mathrm{SD}$ & 0.8 & 0.7 & 0.8 & 0.6 & 0.7 & 0.7 & 1.0 & 0.6 \\
\hline \multirow[t]{2}{*}{ Iron (mg) } & Mean & 23.24 & 24.9 & 26.2 & 25.0 & 23.9 & 22.4 & 20.2 & 21.9 \\
\hline & $\mathrm{SD}$ & 5.8 & 7.6 & 4.0 & 5.5 & 5.5 & 8.4 & 3.6 & 5.7 \\
\hline
\end{tabular}


Table 3. Internal and external load variables for low intensity sessions when adopting a sleep low (LOW) and sleep high approach (HIGH). Data are presented as mean $( \pm \mathrm{SD}) . *$ indicates values are significantly greater than day $4 .{ }^{*}$ indicates values are significantly lower than HIGH trials.

\begin{tabular}{|c|c|c|c|}
\hline & Trial & Day 2 - Cycle & Day 4 - Run \\
\hline $55 \%$ Intensity & LOW & $164 \pm 23$ & $5: 15 \pm 0: 19$ \\
\hline$(W$ OR $\min / \mathrm{km})$ & HIGH & $164 \pm 22$ & $5: 09 \pm 0: 12$ \\
\hline $65 \%$ Intensity & LOW & $212 \pm 27$ & $4: 45 \pm 0: 26$ \\
\hline$(W$ OR $\min / \mathrm{km})$ & HIGH & $216 \pm 33$ & $4: 45 \pm 0: 26$ \\
\hline Mean Heart Rate & LOW & $158 \pm 9 *$ & $151 \pm 13$ \\
\hline (bpm) & HIGH & $152 \pm 9^{*}$ & $144 \pm 9$ \\
\hline RER & LOW & $0.84 \pm 0.04^{\# *}$ & $0.76 \pm 0.02^{\#}$ \\
\hline (Respiratory exchange ratio) & $\mathrm{HIGH}$ & $0.87 \pm 0.03 *$ & $0.80 \pm 0.03$ \\
\hline
\end{tabular}


Table 4. s-IgA concentration, flow rate and secretion rate pre- and post-exercise in athletes adopting a sleep low (LOW) or sleep high (HIGH) dietary approach. Data are presented as Mean $( \pm \mathrm{SD}) .{ }^{*}$ Indicates a significant increase from pre-exercise. ${ }^{\#}$ Indicates a significant decrease from pre-exercise. ${ }^{\wedge}$ Significantly greater than all other trials.

\begin{tabular}{|c|c|c|c|c|}
\hline & \multicolumn{2}{|c|}{ Day 2 - Cycle } & \multicolumn{2}{|c|}{ Day 4 - Run } \\
\hline & Pre-exercise & Post-exercise & Pre-exercise & Post-exercise \\
\hline \multicolumn{5}{|l|}{ s-IgA Concentration $\left(\mu \mathrm{g} \cdot \mathrm{mL}^{-1}\right)$} \\
\hline LOW & $162 \pm 82$ & $229 \pm 147^{*}$ & $195 \pm 87$ & $229 \pm 108^{*}$ \\
\hline HIGH & $145 \pm 78$ & $243 \pm 180^{*}$ & $134 \pm 59$ & $224 \pm 136^{*}$ \\
\hline \multicolumn{5}{|l|}{ Salivary Flow Rate $\left(\mathrm{mL} \cdot \mathrm{min}^{-1}\right)$} \\
\hline LOW & $0.62 \pm 0.35$ & $0.50 \pm 0.35^{\#}$ & $0.83 \pm 0.49$ & $0.64 \pm 0.36^{\#}$ \\
\hline $\mathrm{HIGH}$ & $0.74 \pm 0.45$ & $0.59 \pm 0.55^{\#}$ & $0.80 \pm 0.59$ & $0.49 \pm 0.27^{\#}$ \\
\hline \multicolumn{5}{|l|}{ s-IgA Secretion Rate $\left(\mu \mathrm{g} \cdot \mathrm{min}^{-1}\right)$} \\
\hline LOW & $98 \pm 73$ & $92 \pm 49$ & $165 \pm 137^{\wedge}$ & $144 \pm 116^{\wedge}$ \\
\hline $\mathrm{HIGH}$ & $122 \pm 136$ & $126 \pm 120$ & $95 \pm 59$ & $101 \pm 71$ \\
\hline
\end{tabular}




\section{$361 \quad$ Figure Caption List}

362

363 Figure 1. Overview of the randomized crossover design for elite triathletes undertaking two four-day

364 experimental trials, inclusive of a $48 \mathrm{~h}$ breakdown of the carbohydrate periodization around key high 365 intensity (HIT) and low intensity (LIT) sessions.

367 Figure 2. Concentrations of interleukin-6 (A and B) and hepcidin-25 (C and D) on days 2 and 4 368 when adopting a sleep low (LOW) or sleep high approach (HIGH). * Indicates a significant increase 369 from pre-exercise. \# Indicates a significantly greater response compared both the HIGH condition and 370 running trials. Data presented as Mean $( \pm \mathrm{SD})$. 


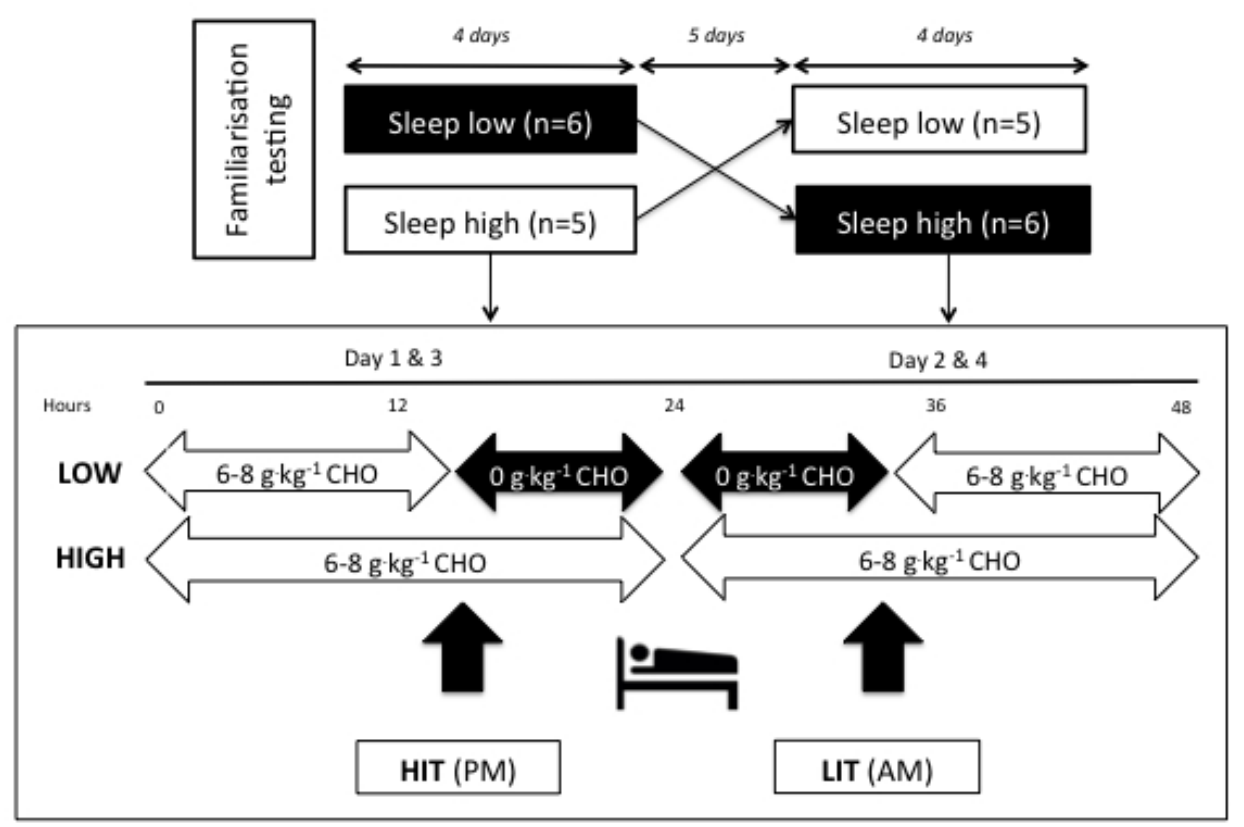

Figure 1. Overview of the randomized crossover design for elite triathletes undertaking two four-day experimental trials, inclusive of a $48 \mathrm{~h}$ breakdown of the carbohydrate periodization around key high intensity (HIT) and low intensity (LIT) sessions.

$211 \times 158 \mathrm{~mm}(72 \times 72 \mathrm{DPI})$ 


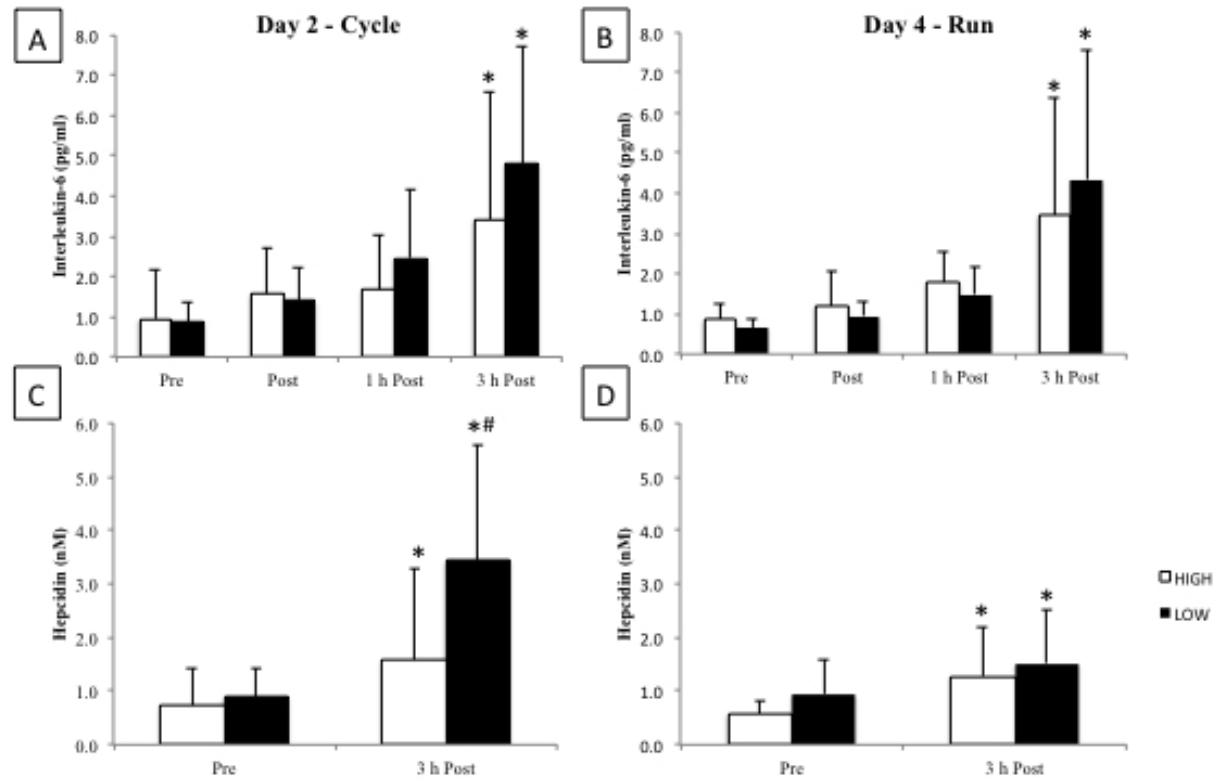

Figure 2. Concentrations of interleukin-6 (A and B) and hepcidin-25 ( $C$ and $D)$ on days 2 and 4 when adopting a sleep low (LOW) or sleep high approach ( $\mathrm{HIGH})$. * Indicates a significant increase from preexercise. \# Indicates a significantly greater response compared both the HIGH condition and running trials. Data presented as Mean ( $\pm \mathrm{SD})$.

$211 \times 132 \mathrm{~mm}(72 \times 72 \mathrm{DPI})$ 